\title{
Produção e reprodução no espaço familiar: trabalho a domicilio na produção de calçados - Franca-SP
}

Production and reproduction in the Family sapce: home work in shoe production Franca-SP.

\section{Onilda Alves do Carmo*}

Resumo: O presente estudo busca apresentar os resultados de uma pesquisa realizada em 2016 com famílias operárias que realizam partes do processo da produção do calçado em suas casas. O objetivo da pesquisa realizada foi o de compreender o lugar dessas famílias no processo produtivo das fábricas de calçado de Franca e sua contribuição na produção de mercadorias. Há que se apontar que a pesquisa possibilitou uma aproximação com essa realidade e permitiu apreender algumas particularidades das estratégias utilizadas pelo capital deste setor de produção para sair da crise que se instalou no país, intensificada a partir da década de 1990.

Palavras Chave: ordem mundial - trabalho a domicilio - precarização - trabalho por peça divisão sexual do trabalho.

\begin{abstract}
The present study seeks to present the results of a survey conducted in 2016 with working families who carry out parts of the footwear production process in their homes. The objective of the research was to understand the place of these families in the productive process of the shoe factories in Franca and their contribution in the production of goods. It should be noted that the research enabled an approximation with this reality and allowed to apprehend some particularities of the strategies used by the capital of this production sector to get out of the crisis that was installed in the country, intensified since the 1990 s.
\end{abstract}

Keywords: world order - homework - precariousness - work by piece - sexual división of labor.

\footnotetext{
* Doutorado em Serviço Social pela Universidade Estadual Paulista Júlio de Mesquita Filho (2008). Pósdoutorado na Facultad de Filosofia e Historia Universidad de La Habana - Departamento de Sociologia (2012). Professor assistente doutor - da Universidade Estadual Paulista Júlio de Mesquita Filho.
} 


\section{Introdução}

A Nova Ordem Mundial imposta pelos países do capitalismo central que, para sair da crise que assolava suas economias, desde a década de 1970, passam a buscar novos mercados para exportação de suas mercadorias, essa nova ordem consiste no fenômeno da mundialização do capital (CHESNAIS, 1996).

A crise dos anos 1970, com certo atraso, repercutiu na economia brasileira, afetando sobremaneira as indústrias e provocou mudanças. A indústria calçadista, não ficou imune a essas mudanças. A indústria calçadista de Franca, SP passou a buscar novas estratégias para sair da crise. Entre as estratégias estava o aprofundamento da terceirização de partes do processo de produção na modalidade de trabalho externo às fábricas. Trabalho esse realizado nas bancas de pespontos domiciliares, envolvendo operários/as e suas famílias ${ }^{1}$.

Esta nova configuração do processo produtivo do calçado em Franca provocou algumas mudanças na forma com as famílias entrevistadas organização as tarefas domésticas e o trabalho de produção - costura do calçado. A família² ${ }^{2}$ para além do espaço das relações, familiares, do cuidado, ela, dentro das suas várias configurações, se organiza buscando alcançar uma renda que lhe permita garantir o mínimo de sobrevivência. Para a teoria crítica, a família se constitui em unidade de reprodução da força de trabalho para o mercado e produção de uma renda para o consumo. Na pesquisa realizada, pode-se perceber que as famílias, ao transformar parte dos espaços de sua casa, se transformar em pequena unidade de produção para as bancas e fábricas de calçado- é dessa realidade que o presente artigo procura abordar. As reflexões apresentadas neste estudo é o resultado de uma pesquisa, realizada em 2016 com $10^{3}$ (dez) famílias operárias que trabalham com bancas de pesponto e atividades de costura manual de calçados para fábricas de calçados.

A pesquisa, se propôs a compreender e analisar o lugar destas famílias operárias na nova configuração do processo produtivo e sua contribuição aos novos padrões de

\footnotetext{
${ }^{1}$ Abordo a "família" como a força-de-trabalho que realiza as atividades de produção no espaço da casa.

${ }^{2}$ Não pretendo abordar os diferentes conceitos de famílias, nem mesmo as diferentes configurações familiares. Estou tomando o conceito de família operária proposto Fausto Neto (1982).

${ }^{3}$ A amostra foi definida por saturação de informações, constituindo-se, então, de 10 famílias que realizam o trabalho domiciliar da produção do calçado, que se dispuseram participar da pesquisa.

Além das famílias também foi feita uma entrevista com o presidente do Sindicato dos Sapateiros de Franca, Sr. Sebastião Ronaldo, de forma a obter um olhar mais abrangente do processo do trabalho domiciliar.
} 
acumulação capitalista, a partir da terceirização de determinadas fases da atividade produtiva da indústria calçadista de uma cidade no interior que transferiu partes do processo produtivo de calçado para as famílias que montaram bancas que muitas repassam o trabalho para outras famílias contratadas por elas.

A partir da análise dos resultados da pesquisa com as famílias, foi possível desvendar particularidades que demonstram a existência de um trabalho que produz mais-valia, subsumido no trabalho doméstico não remunerado.

A Pesquisa também permitiu a aproximação com uma modalidade de trabalho que é a produção de calçados, não mais no espaço formal e institucionalizado da fábrica, mas no domicilio, espaço informal da casa dos/as trabalhadores/as.

Compreender a situação das famílias operárias que trabalham no próprio domicilio em atividades que compõem o processo da produção de calçados, pressupõe a aproximação e a observação apuradas dos processos de inserção, de forma terceirizada e precarizada, da força de trabalho. O que nos parece fundamental consiste em delinear uma concepção de investigação com o olhar atento para captar o movimento do real, numa perspectiva sociopolítica que seja relevante para compreender a situação de trabalho destas famílias, quanto para a orientação de uma prática e compromisso com o projeto político da classe trabalhadora, como preconiza o Projeto Ético-Político da Profissão do Serviço Social.

Aproximar das famílias que realizam trabalhos a domicílio para as fábricas de calçados, conhecê-las, estabelecer diálogo com elas para, a partir de aí levantar as informações necessárias para realizar a coleta de dados e sua análise, foi um processo enriquecedor.

Esta pesquisa ajudou a trazer à tona aspectos que, muitas vezes, ficam subsumidos nas análises mais geral do processo de acumulação que é a experiência de famílias que no seu processo de produção e reprodução da vida cotidiana se constituem como um espaço ampliado das fábricas. Ou seja, não apenas reproduzem a força de trabalho futura para o capital, mas também, contribuem diretamente com a produção de mercadorias, fazendo de seus lares também unidades de produção.

\section{Espaço doméstico e espaço de produção: um lugar comum}


Constatou-se que, a maioria dos/as trabalhadores/as domiciliares é composta por mulheres, contudo e, somente em duas das unidades visitadas a mulher é a proprietária da banca ou banqueira ${ }^{4}$. Nas demais, as mulheres trabalham para a fábrica ou para um banqueiro, todos homens, sem nenhum vínculo empregatício.

A maioria das bancas está organizada e dirigida pelas mulheres, contudo, não são elas que tomam as decisões nos "negócios". Em 8 (oito) delas a propriedade da banca pertence aos homens, são eles os que assumem as relações entre a banca e a fábrica, são eles que negociam os preços, são eles que fazem as compras de materiais, mas são as mulheres que realizam a atividade da banca. Eles são cônjuges ou pais. Porém, todos os membros da família que não tem um emprego formal, ocupam-se do trabalho no domicílio. Contudo, aparece uma clara divisão sexual do trabalho e aqui inclui-se o trabalho o trabalho doméstico, não remunerado (Hirata 2002), realizado, via de regra, pelas mulheres.

Os dados apontaram que a maioria das/os entrevistadas/os está nesse trabalho há mais de dez anos e, como em quase todas as bancas as mulheres realizam também a atividade de colação ${ }^{5}$, portanto estão expostas a produtos tóxicos durante muitos anos.

Com algumas particularidades próprias desse processo, pode-se concluir que a produção nas bancas é um empreendimento familiar. Isto significa que essas famílias, para além de uma unidade de reprodução social, transformaram-se em uma unidade de produção. Nestas bancas, as relações familiares estão perpassadas pelas relações de produção, próprias da relação capital x trabalho.

O trabalho de pesponto ${ }^{6}$ e costura manual, por serem atividades que não tem problemas de sequência na produção, ou seja, não depende de estar perto das demais fases da produção, pode ser realizado fora do chão da fábrica, inclusive na casa dos/as trabalhadores/as. Essa estratégia ajuda a diminuir os custos da produção.

\footnotetext{
44 Proprietária (os) ou banqueira (o) são as/os donas/os das bancas. As bancas são as unidades de produção de partes do calçado. São equipadas com maquinas e materiais, ou seja, dos meios para realizar as atividades de pesponto, colagem, costura manual, entre outras. São as/os banqueiras/as que negociam diretamente com a fábrica e pegam o trabalho e depois redistribuem para a família. A costura manual muitas vezes é repassada para outras famílias que acabam trabalhando não diretamente para a fábrica, mas, para seu entreposto que é a banca.

${ }^{5}$ Colação atividade de colagem de peças do calçado. Depois de coladas vão para as máquinas de pesponto.

${ }^{6}$ Pesponto é um tipo de costura que se faz com uma máquina especial. Depois de colada, a peça vai para máquina de pesponto para ser costurada. Acabado esse processo as peças voltam para a fábrica para fazer o acabamento. Algumas bancas faz o traçado do pesponto com a máquina e depois entrega para as famílias que realizam costura manual em casa.
} 
A indústria de calçados é um ramo que tem no trabalho a domicílio e no uso da mãode-obra feminina, marcas tradicionais. Com o advento da revolução industrial, no final do sec. XVIII e princípios do XIX, a tendência à concentração nas fábricas de capital, homens e máquinas, conviveu com uma diversidade de formas transitórias de organização do processo de trabalho (Giacometti,1997, p. 12).

Dentro da empresa, os/as trabalhadores/as têm definido seus horários de trabalho, e ainda que a jornada seja um pouco mais extensa, eles usufruem de alguns direitos trabalhistas tais como: salário, férias, descanso semanal, recebimento por horas extras ou banco de horas. Isso, porém, não ocorre com os terceirizados que em geral têm suas jornadas de trabalho estendidas para 12 até 14 horas de trabalho por dia e, ainda que não haja a presença do "gerente de produção", há o imperativo inadiável de garantir a sobrevivência e sem nenhuma garantia de que estas horas sejam remuneradas. "Se não costurar não ganha" (Laura, 2016). Trata-se, portanto, da extração da mais-valia absoluta (MARX, 1985), centrada prioritariamente na extensão da jornada de trabalho, nas horas trabalhadas.

A pesquisa mostrou que a rotina de trabalho nas bancas, em momentos de maior produção das fábricas, inicia-se as $05 \mathrm{~h} 30$ da manhã e vai até as $20 \mathrm{~h} 00$, que é quando as mulheres passam a se dedicar a alguns afazeres domésticos, tais como preparar o jantar, dar banho e alimentar os filhos. Concluídas estas tarefas, muitas vezes, se há muito trabalho, retornam às atividades da banca e trabalham até as $23 \mathrm{~h} 00$. A jornada de trabalho dessas mulheres nas bancas é muito maior do que as 08horas diárias previstas na legislação trabalhista, vigente até o momento.

Um trabalhador afirmou:

Olha o trabalho aqui não é fácil... como aqui a gente faz além do pesponto e colação, a gente faz também a costura manual para alguns modelos, tem época que é quando a gente ganha melhor, as fabricas traz muito serviço. Aí é paulera, das 5 da manhã até 11 da noite e as vezes até meia noite (JAIRO, 2016) ${ }^{7}$.

As mulheres, além de ficarem diante das máquinas ou na colagem durante horas, elas têm que dar conta também das tarefas da casa e dos cuidados com a família, ou seja, estas mulheres trabalham para reproduzir a força de trabalho para as fábricas e também trabalham na produção de mercadoria para as mesmas, pois a fábrica veio para dentro de sua casa.

Uma trabalhadora explicou como faz para conciliar o trabalho da banca com o trabalho da casa:

\footnotetext{
${ }^{7}$ Idem.
} 
Eu levanto lá pras 6:30, 7:00, venho trabalhar, ai depois eu vou lá, põe... afogo um arroz, venho colo uma peça, vou lá afogo um feijão, venho colo outra peça ... faço assim, meu horário de almoço é assim, aí eu cabo de... termino o almoço, não tenho tempo de sentar na mesa, venho pra cá, muitas vezes como aqui mesmo...quando é época que tem que entrega serviço, ai depois que eu...Aí deixo, levo a louça tudo, deixo lá a louça, á noite a hora que eu paro; lá para as 10 o 11 horas da noite e vô dá uma organizada na minha cozinha...pra poder tomar um banho e dormir, é essa a minha rotina (LAURA, 2016) ${ }^{8}$.

Isso revela a particularidade do trabalho feminino e sua funcionalidade para a reprodução da força de trabalho e para a acumulação propriamente dita (Hirata, 2002). A família e a residência do/a trabalhador/a funcionam como espaços consolidados como extensão da própria fábrica e é parte do processo de precarização laboral.

$\mathrm{Na}$ residência o/a trabalhador/a mescla espaço do lar - relações familiares e espaço de produção de mercadorias - relações econômicas, relações familiares e relações de trabalho. Os membros da família se autofiscalizam e fazem dos cômodos da residência extensões das fábricas. Trata-se, em outras palavras, de uma unidade produtiva fora da fábrica que deve funcionar autonomamente, por conta própria, ainda que articulada a um objetivo comum: contribuir com a produção de sapatos.

O depoimento de Laura (2016) demonstra o quanto a fábrica ocupa todos os espaços do "lar" e das atividades do espaço doméstico, destinadas a garantir a sobrevivência. O convívio da família se mistura com as atividades da fábrica e isto não é percebido pelas trabalhadoras entrevistadas. Quando indagadas como era para elas desenvolver o trabalho para a fábrica e ao mesmo tempo fazer o serviço doméstico, a maioria delas respondeu: "é puxado, mas é tranquilo".

Os depoimentos, além de explicitarem a longa jornada de trabalho, também demonstram o quanto as atividades domésticas estão perpassadas pelas atividades do trabalho produtivo ${ }^{9}$. Pela pesquisa foi possível observar que as atividades do trabalho da banca e as atividades do trabalho doméstico estão imbricadas uma na outra. Ou seja, as atividades próprias do espaço doméstico (preparar a comida, cuidar da roupa e da casa, entre outras) e as atividades de produção são realizadas no mesmo espaço. Como este é o espaço das relações familiares, as relações de produção não são percebidas e acabam subsumidas e

\footnotetext{
8 Idem.

${ }^{9} \mathrm{O}$ trabalho produtivo é o que produz valor e não só o valor necessário à reprodução da força de trabalho, mas também produz mais-valia, ou seja, o lucro para o capitalista. Para Marx “só é produtivo o trabalho assalariado que produz capital" (MARX, 1980, p.32)
} 
invisibilizadas pelo espaço doméstico. Esta atividade, por ser realizada na casa da família e, também, por estar incluída em uma forma determinada de relações de trabalho - precarizado, aviltado, invisível, esconde a natureza de sua relação invizilibizando a relação capital X trabalho, não permitindo que os/as trabalhadores/as se deem conta do processo de exploração e expropriação da mais valia absoluta. Ainda que a tendência geral da intensificação do processo de expropriação da mais valia relativa, devido ao avanço tecnológico, apontado por Antunes (2005) e outros, no caso dos/as trabalhadores/as nas bancas de pesponto, o que ocorre é a intensificação da extração da mais valia absoluta.

Tomando em conta a quantidade de horas trabalhadas, pode-se verificar, a quantidade de força de trabalho dispendida pela/o trabalhadora/or para obter uma renda por mês, que, segundo eles giraria em torno de $\$ 1.800,00$. Essa é a particularidade do trabalho pago por peças. Quanto mais a/o trabalhadora/or produz, mais ele ganha, mas a exploração é maior e o roubo do tempo de vida futuro se intensifica por meio do desgaste precoce da força de trabalho.

Para Marx (1985)

Dado o salário por peça, é naturalmente do interesse pessoal do trabalhador aplicar sua força de trabalho o mais intensamente possível, o que facilita ao capitalista elevar o grau norma de intensidade. Do mesmo modo, é interesse pessoal do trabalhador prolongar a hora de trabalho, pois com isso sobe seu salário diário ou semanal. Ocorre assim, a reação já descrita ao tratarmos do salário por tempo, abstraindo o fato de que o prolongamento da jornada de trabalho, mesmo permanecendo constante o salário por peça, implica em si e para si uma baixa de preço do trabalho (MARX, 1985, Vol. 3, p. 141 e 142)

Quanto à renda, o valor do trabalho é calculado por peças, ou seja, por pares de peças. O trabalho é calculado pela quantidade de peças que a/o trabalhadora/or consegue costurar, colar ou pespontar.

Marx (1985) - afirma que o salário por peças é forma de salário por tempo.

o salário por peça é, ... apenas uma forma modificada do salário por tempo. A qualidade do trabalho é aqui controlada mediante o próprio produto, que tem de possuir qualidade média se o preço por peça dever ser pago integralmente. Desse modo, o salário por peça se torna fonte mais fecunda de descontos salariais e de redes capitalista. Ele proporciona ao capitalista uma medida inteiramente determinada para a intensidade de trabalho. (MARX, 1985, Vol. 3, p. 140).

O salário por peça dá a falsa ideia de certa liberdade, pois, a/o trabalhadora/or acredita que é ela/ele que decide quanto vai ganhar, porque depende dela/e a quantidade 
que vai produzir. No entanto, o que determina o ritmo da produção, em última instância, é a fábrica. O salário por peça é uma forma particular de exploração, pois segundo Marx (1985) o salário por peça é a forma de salário mais adequada ao modo de produção capitalista. "Em outras palavras: o salário por peça é rebaixado na mesma proporção em que cresce o número de peças produzidas durante o mesmo tempo (MARX, 1985, Vol. 3, p. 142)

Ao perguntar quem define o valor do trabalho, todas/os responderam que se faz de comum acordo entre a fábrica e a banca. Ocorre que a fábrica, ainda que não tenha a propriedade dos meios de produção na sua totalidade - as máquinas, por exemplo, utilizadas pelas bancas é de propriedade das/os banqueiras/os -, tem o controle do processo produtivo, portanto do poder de decisão sobre o mesmo. Dessa maneira, quem tem o poder de decidir sobre o valor do trabalho é a fábrica.

Com relação aos custos para realizar o trabalho de pesponto, colação ou costura manual, a maioria afirmou ser de responsabilidade das/os banqueiras/os. Ou seja, o capital, distribui os custos da produção com as/os trabalhadoras/es.

Se a máquina utilizada pela banca tiver qualquer problema e necessite fazer algum tipo de reparo, ele deverá ser feito por conta da/o banqueira/o. Mesmo no caso em que a máquina é alugada, quem arca com o reparo é quem trabalha com ela.

As pessoas entrevistadas, informaram que todo material utilizado para o trabalho na banca - linha, cola - é fornecido pela fábrica, mas o custo dele é deduzido do valor que o/a banqueiro/a teria que receber no momento da entrega do "serviço". Isto confirma a premissa de em períodos de crise estrutural, o capital divide os custos da produção com os/as trabalhadores/as.

Pelas entrevistas foi possível constatar que as empresas mantiveram no seu interior atividades do processo consideradas como de maior exigência, seja em termos de garantir o menor prejuízo, seja garantir que o produto mantenha sua "qualidade". Estas atividades são: corte do couro que requer precisão do profissional para que não se desperdice material e a atividade da fase final para garantir a qualidade do produto: montagem e acabamento (Navarro, 2006).

No processo de acabamento o calçado é desenformado, arrancado da forma onde foi montado, quando são feitos os últimos retoques e aplicado pasta. Em seguida, o sapato é manchado ou lustrado, de acordo com modelo, realizando assim o final das etapas da 
montagem e representa o acabamento final do produto antes de ser embalado, faturado e ganhar corpo nas vitrines.

Como no mundo das mercadorias, elas aparentemente ganham vida, antes que o calçado alcance essa vida fora da fábrica, ele ainda passa pelo controle de qualidade feito pelo revisor que busca sinais de alguma imperfeição. Após, o sapato segue para a expedição, sessão responsável por embalar as caixas de sapato de acordo com as fichas para que seja possível o embarque e entrega ao cliente.

Uma característica muito forte do perfil dos sujeitos que trabalham nas bancas é a sua constituição: a grande maioria é formada por público feminino. Brito e Oliveira (1997) destacam que, ao longo dos anos, a realidade sexuada do trabalho foi se modificando. Ao discutir a hierarquia de trabalho em uma indústria têxtil no Rio de Janeiro, os autores verificaram que as mulheres estão limitadas a uma única seção, com restrita possibilidade de ascensão profissional. "A divisão sexual do trabalho não é apenas visível ao nível das seções, mas também na forma como o trabalho é organizado e realizado.

No empeçamento, uma das grandes características do trabalho feminino é ser realizado de forma estática sob uma vigilância constante" (BRITO; OLIVEIRA, 1997, p. 248). O setor calçadista em Franca guarda semelhança com a realidade da indústria têxtil, pois nas fábricas de produção de calçado, apesar de haver a presença de mulheres, a maioria das atividades são realizadas por homens.

Lourenço (2010) constatou que dentro das fábricas, em geral, as mulheres realizam atividades de menor uso tecnológico. Sua presença se dá, em grande parte, nas atividades carimbação ${ }^{10}$ e chanfração ${ }^{11}$ (LOURENÇO, 2010). Nas bancas de pesponto em Franca, observase que nestes espaços predominam o público feminino, sendo a fábrica de sapatos ainda um espaço masculino. A posição social das mulheres no mercado de trabalho segue os padrões ideológicos da sociedade. No caso das mulheres das famílias que fizeram parte do universo de pesquisa, as mulheres reproduzem as relações de sexo/gênero, pois ainda que se ocupem das atividades de produção nas bancas, ainda são responsáveis e assumem as tarefas do espaço doméstico. Algumas relataram a rotina diária de trabalho que indica uma jornada de 10 a 12 horas por dia (LAURA, 2016).

\footnotetext{
${ }^{10}$ Carimbação é feito na palmilha e na língua do sapato com máquina quente.

${ }^{11}$ Chanfração é o trabalho de afinar as laterais das peças para colar umas nas outras e assim não dar relevo no pesponto. Se ficar relevo pode machucar os pés.
} 
Brito e Oliveira (1997, p.251) enfatizam que a apropriação da tecnologia mais avançada ainda fica a cargo dos homens, enquanto que "[...] ficam designadas para as mulheres as máquinas mais antigas, que exigem menor qualificação e uma atuação coerente com o que se costuma definir como qualidades femininas, inerentes ao seu sexo". A dominação entre os sexos não se restringe ao convívio familiar. As mulheres conquistaram a cidadania por meio das lutas ao longo da história, mas ainda há muito que avançar em todas as áreas. $\mathrm{O}$ trabalho masculino continua sendo mais valorizado que o realizado pelas mulheres nas mesmas funções.

A partir da Revolução Industrial um contingente de mulheres (Nogueira, 2006), em sua maioria brancas ${ }^{12}$, gradativamente vão se proletarizando, mas seguem responsáveis pelo cuidado espaço doméstico, incluindo aí o cuidado com as pessoas.

O trabalho das bancas, aparece com o processo de terceirização no setor calçadista de Franca, como forma de reestruturação produtiva típica dos anos 1990, transferiu os custos da produção de mercadoria para as bancas, mantendo sob o controle das empresas os processos essenciais para a produção do sapato, sobretudo aqueles considerados fundamentais para o controle de qualidade. As empresas reduziram drasticamente os gastos para a realização das atividades mais operacionais e intermediárias (meios de produção em geral como capital constante - MARX, 1983), bem como os encargos trabalhistas (como capital variável), ampliando substancialmente a precarização dos trabalhadores (ANTUNES, 2003). Alteraram, com isso, a composição orgânica do capital (MARX, 1985) maximizando lucros seja sobre o valor extraído da força de trabalho precariamente contratada naquelas funções permitidas, seja reduzindo os custos de produção em geral. A forte presença do trabalho feminino e as particularidades contidas neste tipo de força de trabalho (especificamente o valor da sua força de trabalho se comparada à masculina) intensificam o processo de expropriação e maximização dos lucros em uma economia mundializada.

Como visto, o espaço formal da produção de mercadorias e o espaço informal das relações familiares, no processo de trabalho das bancas, ficam imbricados e um subsumindo no outro.

Quando nos propusemos a conhecer e analisar a realidade das famílias operárias, nos propusemos também a explicitar quem são esses sujeitos, identificando o seu perfil social

\footnotetext{
${ }^{12}$ As mulheres historicamente, desde o período escravocrata, já estavam nas "ruas" trabalhando para sustentar seus filhos - sua família.
} 
mais geral, mas também conhecer a que grupos eles pertencem, pois o ser humano é um ser em relação, seja ela dentro do espaço familiar da "casa", seja ela no espaço da "rua".

A "rua" significa o espaço público, fora da "casa". Contudo como espaço, a "rua" também contribuiu para a construção das identidades de gênero. Os estudos de gênero, em geral, apontam as diferenças nos papéis sociais historicamente construídos, indicando os papéis do espaço doméstico - da "casa" para as mulheres e os papéis da "rua" para os homens. Evidentemente que, a partir das lutas das mulheres, esta concepção de papéis já mudou. Hoje não se pode falar em papéis determinados, contudo, ainda prevalece na maioria das famílias e das sociedades, o lugar da "casa" como o lugar da mulher.

Mas o que é a "casa"? Quando falamos na casa, em geral, nos reportamos à ideia de lugar de chegada, moradia, de relações.

Na casa vivem as famílias e estas são formadas por pessoas que se relacionam no espaço da casa ${ }^{13}$. Nesse estudo, estamos tomando casa como espaço físico de organização da família. Neste sentido, foi possível observar que a maioria das famílias dos sujeitos da pesquisa organiza-se em um espaço físico menor do que o necessário para a acomodação de todos os membros. Ou seja, a moradia destas famílias não pode ser considerada como moradia digna (Maricato, 2011).

Como não existe um modelo de família e não existe "arranjos" familiares e sim, configurações familiares, estou tomando família como grupo de pessoas que coabitam e estabelecem relações no sentido de garantir os cuidados, a acolhida e a esforço coletivo de alcançar a sobrevivência das pessoas. No universo pesquisado havia famílias compostas por casais heterossexuais, mães sozinhas com filhos, avós com netos e uma família formada por dois irmãos.

Devido ao pequeno espaço físico, há poucas chances de se respeitar a individualidade e a intimidade de cada uma das pessoas (adultos, jovens e crianças) que aí convivem. Crianças, jovens e adultos, em cada fase, têm um modo diferente de lidar com o corpo, com a sexualidade, com as relações e com a própria intimidade. Como se dará o processo de construção das identidades (social e psicológica) se ele pressupõe identificação e outro de diferenciação, em um espaço que não dá lugar para a experiência dos processos individuais

\footnotetext{
${ }^{13}$ Aqui há que apontar que, ainda que reconheça as particularidades do processo de constituição e construção de muitas famílias, de modo particular as famílias empobrecidas pelo modelo de desenvolvimento econômico, que não consegue acessar o direito à moradia digna, abordarei o tema da casa como espaço de moradia, de relações familiares, para explicitar a apropriação que a fábrica faz deste espaço.
} 
de construção da identidade do ser que é social e único ao mesmo tempo? A identidade sexual, embora tenha uma dimensão social, no processo de sua construção necessita de espaços privados para a intimidade.

Neste sentido, a casa se constitui no espaço de explicitação e significação das subjetividades de todas as pessoas que aí convivem e realizam suas experiências. Experiência como ação que engloba subjetividade, relação com o outro. Experiência como conjunto de elementos que configuram a atuação e a percepção da pessoa no mundo: subjetividade, relação com os outros, com a natureza e com o sagrado e a forma como autocompreende a sua atuação.

A casa é, portanto, o espaço no qual a família se constitui e se relaciona. Nela se desenvolvem os processos de socialização dos papéis e a construção das responsabilidades. A casa, enquanto espaço doméstico das relações, pertence à mulher. O homem, em geral, foi excluído da "casa", pois a esfera de sua atuação é a "rua" (BILAC,1978, p. 41). Contudo, o homem, a partir das construções sociais dos diferentes papéis, foi criado como ser que detém a supremacia na relação, seja na "casa", seja na "rua". Esta supremacia está baseada na sua condição de macho (Saffioti, 1987).

No caso das famílias que realizam trabalhos a domicílio nas bancas de pesponto, a forte presença da mulher não indica, necessariamente, uma relação de igualdade com o homem, em especial naquelas em que a banca é de propriedade do marido ou do pai. Essas mulheres têm dupla jornada de trabalho, enquanto os homens trabalham somente na banca. A divisão sexual do trabalho, no caso das famílias entrevistadas, a mulher assume a maior parte do trabalho produtivo na banca e a totalidade das tarefas do espaço doméstico, consideradas como trabalho reprodutivo, subsumido no trabalho produtivo e vice-versa (Kergot apud Hirata, 2009).

No trabalho realizado nas bancas, há uma importante particularidade: as duas formas e expressão da categoria trabalho - profissional e doméstico - são realizadas dentro do mesmo espaço - o da "casa". Portanto, no cotidiano destas famílias operárias, o seu espaço familiar, é perpassado pela lógica do trabalho produtivo, objetivado, alienado, estranhado.

O processo histórico de transformação do trabalho em mercadoria constituiu-se de um processo que incluiu a desvinculação do trabalhador dos meios de produção e sua transformação em trabalhador coletivo e, sua força de trabalho em trabalho alienado, realizado no espaço destinado à produção de mercadorias, separado do espaço da casa 
(ANTUNES, 2005). Historicamente esse espaço da produção de mercadorias é coletivo, no qual se apresentam outros/as sujeitos que aí comparecem para vender sua força de trabalho e, que, portanto, desenvolvem ações e relações que os/as identificam enquanto classe - sujeito coletivo. O que não ocorre com o/a trabalhador/a realizando, isoladamente, a mesma atividade no espaço particular de sua residência.

Para Marx, o trabalho, no capitalismo, como trabalho abstrato-estranhado, tem como finalidade última garantir a reprodução da força de trabalho: "Dada existência do indivíduo, a produção da força de trabalho consiste em sua própria reprodução e manutenção" (MARX, 1985, Vol. 3, p.141).

Os processos sociais de construção de uma família variam de grupo para grupo, de sociedade para sociedade, e as mudanças operadas na família devem ser entendidas no seio das transformações ocorridas no nível macro da sociedade. A família é considerada uma das instituições mais antigas e, segundo Engels (2002), desde 1861 quando Johann Jakob Bachofen publicou o Direito Materno, ela é estudada pela história. Em 1871, Lewis Henry Morgan publicou sua obra Systems of Consanguinity anda Affinity of the Human Family, na qual apresentou sua teoria evolucionista de família.

Para Engels (2002), a ordem social está condicionada pelo grau de desenvolvimento do trabalho e da família. Quanto menor o grau de desenvolvimento do trabalho, menor a riqueza e, segundo o autor, maior a influência dos laços de parentesco sobre o regime social.

A família tem se constituído em objeto de estudo das várias ciências e, quase todos convergem para colocar a família como espaços de relações, de convívio e de construção de identidades; o espaço da família estava separado do espaço público, da rua, da produção.

Os estudos mais recentes sobre família têm trazido uma perspectiva de família como unidade de reprodução social, neste artigo estou tratando a família como unidade social cuja materialidade de sua existência e configuração se dá em uma sociedade capitalista. Nesta perspectiva, a família é uma instituição social que se realiza dentro de uma situação de classe, enquanto uma unidade de reprodução da força de trabalho (FAUSTO NETO, 1982). A família realiza a reprodução da força-de-trabalho e a reprodução ideológica de continuidade na reprodução das relações, como uma unidade social. Como unidade social realiza dois processos:

reproduz o trabalhador, enquanto força de trabalho - que é a dimensão material da reprodução e a reprodução ideológica não só da força de trabalho atual, mas também como dos futuros trabalhadores (FAUSTO NETO, 1982, p. 18). 
A família também é entendida como unidade de renda, onde todos os membros trabalham para compor uma renda que garante a sobrevivência da família. Nessa unidade de renda, os membros estão inseridos em atividades das quais retiram o valor para contribuir com o grupo familiar. Aquelas/es que não encontram trabalho no mercado de trabalho, realizam as atividades na "casa", trabalhos inseridos na órbita do consumo familiar, mas estas atividades contribuem fundamentalmente para constituição e manutenção da mercadoria força de trabalho que é vendida ao capital.

No caso das famílias operárias que realizam trabalho à domicilio nas bancas, o que se pode apreender é que elas realizam não só os dois processos - de formação da mercadoria força de trabalho e a sua reprodução futura -, mas também realizam o processo de produção, antes realizado no espaço da fábrica, localizado fora do espaço doméstico. Desta forma as famílias operárias que trabalham a domicílio para as fábricas se realizam também como unidade de produção, ou seja, elas realizam no seu cotidiano os dois processos intrínsecos ao modo de produção capitalista o de produção e reprodução das mercadorias.

A produção industrial, antes uma atividade realizada e materializada dentro da fábrica, espaço no qual reunia a força de trabalho que saia do espaço doméstico - da "casa", seguia até a fábrica e lá vendia sua mercadoria força de trabalho para ser utilizada no espaço da fábrica, separado da sua "casa". No trabalho das bancas, a fábrica ocupa a "casa" e desaparece o espaço - o hiato entre a "casa" e a "fábrica".

A fábrica ocupou de tal modo a "casa" que é possível encontrar bancas em que as máquinas estão localizadas na sala ou mesmo na cozinha, em outras está localizada na garagem. Em algumas casas visitadas para a pesquisa, as peças e as linhas estavam em cima de um sofá ${ }^{14}$. Ou seja, a fábrica ocupou também o lugar do convívio da família, o lugar de receber as visitas. Em outra casa, a máquina estava na cozinha e nesse ambiente a trabalhadora preparava a comida, comia e fazia o pesponto, mas também fazia o serviço de colação. Neste ambiente se misturavam os aromas, o da comida com o da cola.

A família, enquanto unidade de produção, ainda que em uma escala muito pequena, guarda algumas particularidades próprias do processo de produção realizado dentro da fábrica, pois o ritmo do cotidiano do "lar" é definido pela quantidade de trabalho a ser

\footnotetext{
${ }^{14}$ Na sala estavam o sofá, a TV, a máquina de pesponto e os materiais de trabalho: linha, cola, peças de couro e de metais.
} 
realizado. A jornada de trabalho é determinada pelo ritmo da exigência da fábrica. As tarefas domésticas são feitas nos intervalos do trabalho na produção ou então, ao final do dia, quando termina o trabalho na banca. Portanto, a vida familiar e a vida laboral é um continum o que permite um grau ainda maior de exploração. A casa da família, nesse modo de produção, se transforma em espaço da fábrica.

\section{Considerações finais}

As mudanças econômicas e sociais ocorridas na sociedade brasileira a partir da década de 1990, bem como as medidas de ajustes impostas pela lógica do desenvolvimento econômico implementado no país, atingiram milhares de trabalhadores. As famílias diante dessas mudanças, buscaram e buscam estratégias de sobrevivência. Esse processo de precarização e desregulamentação absorveu parcela importante da força de trabalho feminino. Dessa forma o capital incorpora o trabalho feminino de forma desigual e sua conquista se converte em instrumento de desigualdade entre os sexos

As mulheres das famílias operárias que trabalham a domicilio nas bancas para as fábricas de Franca, não saíram para o mercado de trabalho nas fábricas; a fábrica se mudou para sua "casa". A sua "casa" não é mais o espaço da organização e da convivência familiar, espaço da realização de atividades que produzem mercadoria com valor de uso: criação dos filhos - futura mercadoria força de trabalho, preparo de alimentos que garantem a manutenção, o cuidado das pessoas e, a reprodução da família. Sua "casa" é o lócus de uma unidade de produção de mercadoria com valor de troca. Ela se transforma em espaço da produção e toda a dinâmica da família está perpassada pela lógica da organização da produção própria do espaço da fábrica. No entanto, como os espaços doméstico e fabril não estão explicitados e delimitados, o grau de alienação do trabalho ainda é mais intensificado. $\mathrm{Na}$ atividade da banca a relação trabalho $X$ capital fica escondida, pois como já afirmado, as atividades - domésticas e produtivas - ficam subsumidas uma na outra.

Desta forma, é preciso compreender o processo de reprodução destas famílias e as particularidades de sua inserção na dinâmica da produção de calçados, procurando desnudar e explicitar as relações próprias de cada espaço - da "casa" e da "rua". Neste sentido, é necessário refletir sobre os conceitos de famílias com os quais o Serviço Social está trabalhando. $\mathrm{O}$ trabalho realizado com as famílias, seja no processo de acolhimento, seja no 
processo de intervenção, deve considerar as mudanças ocorridas nos padrões familiares e, particularmente, o papel que elas ocupam no processo de produção e reprodução de mercadorias, portanto na reprodução do próprio capital.

Por fim, é preciso afirmar que as questões aqui levantadas não têm a pretensão de esgotar o debate; ao contrário, elas se colocam como contribuição ao debate, em especial para o Serviço Social, considerando a importância do estudo sobre o lugar e o papel da família operária que trabalha nas bancas de pesponto de Franca.

\section{Referências}

ANTUNES, R. Adeus ao trabalho? Ensaios sobre as metamorfoses e a centralidade do trabalho 9.ed. São Paulo: Cortez; Campinas (SP): Editora da Universidade Estadual de Campinas, 2005.

BILAC, E. D. Família de trabalhadores: estratégia de sobrevivência. A organização da vida familiar em uma cidade paulista. São Paulo: Editora Símbolo, 1978.

BRITO, J.; OLIVEIRA, S. Divisão Sexual do Trabalho e Desigualdade nos Espaços de Trabalho. In: FILHO, J. F. da S.; JARDIM, S. R. (Org.). A Danação do Trabalho: organização do trabalho e sofrimento psíquico. Rio de Janeiro: Te Corá, 1997, p. 245- 263.

CHENAIS, F. A mundialização do capital. São Paulo, Xamã Editora, 1996.

ENGELS, F. A origem da família, da propriedade e do Estado. São Paulo: Cortez, 2002.

FAUSTO NETO, A. M. Q. Família operária e reprodução da força de trabalho. Petrópolis/RJ, 1982.

GIACOMETTI, I. De Volta ao Lar? Trabalho Feminino e Globalização. 1997. Tese de Doutorado em Serviço Social. PUC/SP, 1997.

HIRATA, H. Nova divisão sexual do trabalho? São Paulo: Editora Boitempo, 2002.

KERGOAT, Danièle. Divisão sexual do trabalho e relações sociais de sexo. In: HIRATA, Helena et al. (Orgs.). Dicionário crítico feminino. São Paulo: Editora Unesp, 2009. p. 67-76.

LÊNIN, V. I. O imperialismo, etapa superior do capitalismo. Baixado da Internet Marxists Internet Archive. 2018.

LOURENÇO, E. Â. de S. Trabalho Inglório: processo de trabalho, estranhamento e agravos à saúde no setor calçadista em Franca/SP. In: INÁCIO, J. R.; SALIM, C. A. O Vestir e o Calçar: perspectivas da relação saúde e trabalho. Belo Horizonte: Crisálida, 2010, p. 43-89.

MARX, K. O capital: crítica da economia política. Rio de Janeiro: Civilização Brasileira, 1985. (livro I, II, III). 
Teorias da mais-valia: história crítica do pensamento econômico (Livro IV de O capital). Vol. I. São Paulo: Civilização Brasileira, 1980.

NAVARRO, V.L. Trabalho e trabalhadores do calçado. A indústria calçadista de Franca: das origens artesanais à reestruturação produtiva. São Paulo: Expressão Popular, 2006.

NETTO,P. J. Serviç̧o Social e Capital Monopolista. São Paulo/SP: Cortez Editora, 1992.

NOGUEIRA, C. M. O Trabalho duplicado: a divisão sexual no trabalho e na reprodução: um estudo das trabalhadoras do telemarketing. São Paulo: Expressão Popular, 2006.

SAFFIOTI, H. I. B. O poder do macho. São Paulo: Expressão Popular, 1987.

Recebido em: 18.05.2020

Aceito em: 22.06.2021 